\title{
A TEORIA WEBERIANA E SUAS MANIFESTAÇÕES NO JORNALISMO: TWITTER E O CASO HAITI
}

WEBER'S THEORY AND JOURNALISM EVENTS IN:TWITTER

AND HAITI CASE

\begin{abstract}
Letícia SALEM HERRMANN LIMA
Mestranda do programa de Comunicação e Linguagens da UTP. Pesquisadora dos processos das novas mídias orientada pela Professora Dra. Adriana Amaral. Professora Universitária e consultora das áreas de Comunicação Social e Marketing. Contato: letícia_herrmann@hotmail.com Pesquisa apresentada para a disciplina de estudos jornalísticos ministrada e orientada pelo professor Dr. Álvaro Laranjeiras.
\end{abstract}

\section{RESUMO}

Este artigo tem como objetivo apresentar a teoria sociológica weberiana nas ações nos indivíduos contextualizando-as nos fatos jornalísticos repercutidos da catástrofe do Haiti. O recorte do estudo foi à utilização da web, representado pelo Twitter, na mobilização social e sua função de levar informação aos indivíduos. Sabe-se que as redes sociais transformaram-se em grandes centros de informação e são impulsionadoras de novos comportamentos humanos. Em catástrofes como a ocorrida no Haiti, a internet contribui para a mobilização mundial, que em anos anteriores era representada em menor participação comparada aos meios tradicionais como o rádio e a televisão. Utilizou-se como reporte teórico estudos sociais de Max Weber, a análise das sociedades realizada por Pierre Bourdieu e o autor J.B. Pinho, que introduz a web nos estudos do jornalismo.

Palavras-chaves: Twitter. Haiti. Internet. Jornalismo Participativo. Weber.

\section{ABSTRACT}

This article aims to present Weber's sociological theory in action in individuals contextualizing the journalistic facts reflected in the disaster in Haiti. The clipping of the study was the use of the web, represented by Twitter, social mobilization and function of conveying information to individuals. It is known that social networks have become major centers of information and are driving new human behaviors. In disasters such as that in Haiti, the Internet contributes to the global mobilization, which in previous years was represented in lower participation compared to traditional media like radio and television. Used as carry-theoretical social studies of Max Weber, the analysis of companies held by Pierre Bourdieu and author J.B. Pinho, introducing the web in the studies of journalism.

Keywords: Twitter. Haiti. Internet. Participatory Journalism. Weber. 


\section{Os Fenômenos Sociais}

Os fenômenos sociais são impulsionados por atitudes inusitadas e desprogramadas. Não existem regras para a conduta humana. Sabe-se que os indivíduos são motivados por diversos fatores que se tornam os responsáveis pelos atos. O precursor da compreensão dos fenômenos sociais foi Max Weber e este artigo terá como base suas teorias para a análise dos fenômenos da comunicação expressa no Twitter.

Maximillion Carl Emil Weber nasceu na Alemanha em 1864 e dedicou-se aos estudos da economia, filosofia e sociologia em prol as ciências e conhecimento humano. Foram suas pesquisas as responsáveis pela reflexão de um indivíduo que não deve ser analisado isoladamente. Max Web foi o precursor da sociologia defendo a idéia de que indivíduos são movidos por fatores diversos e que a constituição do caráter humano é influenciada por ações impulsionadas pela razão, pelos valores, pela emoção e pela tradição.

Pesquisadores dedicaram-se a descoberta de leis gerais para o compreendimento do ser humano, mas hoje se entende que isso não ocorre. Weber, além de conhecer a diferença dos indivíduos, foi inovador em dedicar-se aos estudos de gênero; homens e mulheres com características distintas. Cada indivíduo é único e sua movimentação é influenciável pelo meio que vive, seja em situações gerais ou isoladas.

Segundo Weber, as condutas humanas variam de acordo com as condutas sociais. Os indivíduos são influenciados pela famí- lia, pelo governo, pela religião, enfim, pelos grupos sociais cuja convivência acontece. Outros autores defendiam a igualdade entre as instituições: a igreja, o governo, a escola. Porém, Weber com novos pensamentos indica que estes grupos são constituídos por membros e a medida com que o tempo passa, pessoas diferentes constituem novos grupos, mesmo que estejam situados dentro de sua casta, ou seja: diferentes padres compõem a instituição da igreja, podendo esta, sofrer mutações de seus componentes. Sendo estas pessoas móveis, os grupos são mutantes também.
As instituições sociais não po- dem ser entendidas a partir das funções que cumpram, pois cos- tumam compor múltiplas e va- riadas funções. As funções das instituições sociais são sempre produtos da vontade de seus participantes, e que ainda se- jam anteriores a eles, podem ser modificada conforme a vontade de seus integrantes. (KUSCHIK apud WEBER, 2006, p.25)

Para Weber a nova ciência proposta, sociologia, pretenderia entender e interpretar a ação social, encontrar o sentido para os atos dos indivíduos e buscar entender o significado e o sentido que estão associados aos signos. O fator de peso desta teoria é a análise das "ações humanas", devendo ser contextualizadas para tal. "A ação humana sempre se relaciona às ações de outros sujeitos: portanto, para atuar devo levar em conta a ação que outros realizam e supor um sentido, uma direção, um significado" (KUSCHIK, 2006, p.26). O autor 
define socióloga como "uma ciência que pretende compreender interpretativamente a ação social e assim explicá-la causalmente em seu curso e em seus efeitos" (WEBER, 1972, p.3). Os fenômenos das ações humanas são os principais fatores estudados neste campo.

Ao mencionar os signos como pontos associativos, o autor estabelece a interface entre a sociologia e os princípios da comunicação. Ora, sendo a leitura de signos uma linguagem e esta uma forma de expressão, Weber teoriza que a linguagem somada à ação comunicativa é a comunicação. A partir desde e de outros estudos no campo da comunicação, o pesquisador inicia reflexão sobre a interferência da sociologia na comunicação, representado principalmente pelo poder da imprensa, responsável pela informação dos indivíduos.

Considerando que os indivíduos são movidos por fatores externos para a continuidade de seus atos e que a imprensa, possui papel importante no cotidiano destes indivíduos, percebe-se a participação da imprensa nos processos de formação do caráter humano, seja com informação ou indução de pensamentos. "Weber perceberá como parte do fenômeno da ação racional com relação a fins a medida que a atuação da imprensa está delimitada pela aparição e diferenciação entre o público e o privado". (KUSCHIK, 2006, p. 31)

O surgimento do público é uma conseqüência da própria comunicação, a imprensa produz sua mensagem com a finalidade de destiná-la a alguém. O público surge como uma mercadoria, im- pulsionada pela necessidade dos lucros para a manutenção da própria imprensa que por sua vez, detém a força sobre a "Opinião Pública".

Com estas idéias o sociólogo contribuiu para os estudos da comunicação e fez com que outros autores, baseados em sua teoria, desenvolvessem novos conceitos aprimorando o que já foi estudado. Pierre Bourdieu representa um destes seguidores citando no livro "A economia das trocas simbólicas", às análises weberianas do indivíduo e o papel da sociedade na formação desta persona.

Bourdieu defende que atribuímos simbologia aos objetos e este feito acontece porque os valoramos de acordo com a imposição da sociedade. A mesma sociedade que Weber diz ser um fator mutatório dos indivíduos. "A sociedade é definida como um sistema de relações onde cada elemento traz uma contribuição para o todo". (BOURDIEUR, 1992, p. 21)

A ciência da comunicação aponta para este indivíduo, mencionado por Weber, e para a simbologia que a sociedade atribui aos objetos, sugerido por Bourdieu. A comunicação tem este poder, seja com o jornalismo, aqui representado pela imprensa ou com outras formas de comunicação, como a propaganda ou as relações públicas.

\section{Jornalismo Participativo e o Caso Haiti}

O foco deste estudo é apontar exemplos do poder atribuído ao jornalismo participativo nas pla- 
taformas de $w e b$, relacionado aos fatores que levam o indivíduo a ação, a movimentação, a informação e a comunicação. São exemplos da teoria weberiana do poder da imprensa e de indivíduos mutáveis, representado nas redes sociais, onde o papel maior da imprensa é informar, defender a população e comunicar.

As mudanças comportamentais decorrem da democratização dos computadores e do crescimento considerável de usuários da internet. Em janeiro deste ano, o IBOPE (Instituto Brasileiro de Opinião Pública e Estatística) divulgou o resultado da pesquisa dos hábitos de consumo de internet no Brasil que mostrou um crescimento anual de 10\% comparando 2008 e 2009. O índice de brasileiros conectados passou de $49 \%$ para $54 \%$ em um ano, representando mais de $25 \mathrm{mi}$ lhões de pessoas na rede brasileira (fonte: meio e mensagem). A utilização das redes sociais e microblogs, segundo o Instituto Datafolha, acompanha o crescimento chegando a $81 \%$ para o público mais jovem.

A internet aproxima pessoas, agiliza processos, democratiza a informação, o conhecimento e transforma culturalmente os indivíduos. "A velocidade de disseminação da Internet em todo o mundo deve transformá-la efetivamente na decantada superestrada da informação" (PINHO, 2003, p.49). Os indivíduos trabalham, estudam, buscam novas formas de diversão, os comportamentos mudaram, as sociedades são outras, até a igreja inova oferecendo bênçãos on-line.

Diante de inúmeras redes sociais existentes no mundo, uma delas desponta e conquista espaço nos hábitos dos indivíduos, o Twitter. Considerados por muitos como rede social, aproximando pessoas com afinidades, o criador do microblog, Briz Stone, nega esta afirmação e conceitua o Twitter como "rede de informação", sendo esta a filosofia principal atribuída a ela. "Isso porque os usuários continuamente reportam não apenas o que estão fazendo, mas o que está acontecendo ao seu redor, relatando de terremotos a protestos, entre outros temas que logo repercutem no mundo digital" (Briz Stone, Meio e Mensagem). Os usuários apropriaram-se do Twitter não só para assuntos pessoais, mas a relação em cadeia propiciada pelas conexões é utilizada a favor da informação e das mobilizações sociais, como o fato do terremoto ocorrido no Haiti.

Desde o dia 12 de janeiro, inúmeros meios de comunicação transmitiram notícias da catástrofe do Haiti. O trabalho dos jornalistas tornou-se complicado, devido a pouca estrutura de sobrevivência e possibilidades de transmissão local. Instituições físicas e jurídicas mobilizaram-se em prol a causa, veículos de comunicação solicitavam ajudas ao mundo todo, a solidariedade imperou. Diante do ocorrido, um fenômeno que já vem sendo observado há algum tempo se repete: a participação das redes sociais, especialmente do Twitter na produção de informação e neste caso específico, solicitando donativos aos desabrigados.

A mobilização representa a força do Twitter como ferramenta de comunicação e rapidez no compartilhamento de informa- 
ções entre seus usuários. Em reportagem publicada na edição on-line do Meio \& Mensagem, o jornal comenta que o microblog foi canal de informação até para a imprensa mundial. A internet proporcionou poder a um indivíduo comum, com o domínio da informação nas próprias mãos. Os usuários postaram notícias sobre o local, sobre as vitimas e auxiliaram parentes na busca de desaparecidos, comenta o jornal. "Os veículos de imprensa do Brasil - sobretudo os portais de internet - também recorreram ao Twitter para solicitar informações de brasileiros ou de estrangeiros que presenciaram a tragédia diretamente da capital Porto Príncipe".

E são estes indivíduos, modificados por hábitos tecnológicos, que contribuem para o jornalismo participativo em todo o mundo. Não possuem a formação acadêmica, mas desejam informar a população, assim como os jornalistas. No dia 13 de janeiro o tópico mais postado no Twitter estava relacionado ao Haiti, pedindo auxílio e donativos às vítimas.

Percebe-se então, a presença do jornalismo participativo, que contribui ao jornalismo em seu processo social, a possibilidade de informar atribui um poder até então nunca possibilitado ao cidadão comum. Mas a participação do usuário precisa ser ponderada ao se analisar informações. $\mathrm{O}$ site Globo.com divulgou a enormidade de usuários que com seus posts ajudaram o trabalho da imprensa, porém tiveram aqueles que sem saber o poder atribuído a ferramenta, informavam fatos não ocorridos, como é o caso de um tweet dizendo que companhias aéreas levavam médicos e enfermeiros gratuitamente ao país, gerando expectativa e desilusão à população haitiana, pois nenhum avião tinha autorização para fazer aterrissagens locais naquele momento.

Eis a diferença do trabalho da imprensa e da participação do usuário. É necessária a averiguação das fontes antes de mandar uma informação ao ar, valeria o preparo jornalístico neste caso ou o bom senso dos participantes do Twitter. Um ponto de mobilização no Twitter foi representado pelo happer Haitiano Wyclef Jean, criador da ONG Yele.org, cuja finalidade é ajudar a população de seu País. O site disponibiliza fotos do cantor, do Haiti, links para diversas redes sociais, sendo a primeira delas o Twitter, e espaço destinado para doações financeiras on-line.

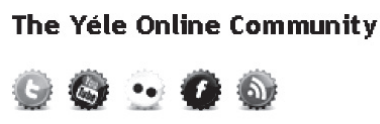

Text Your Support

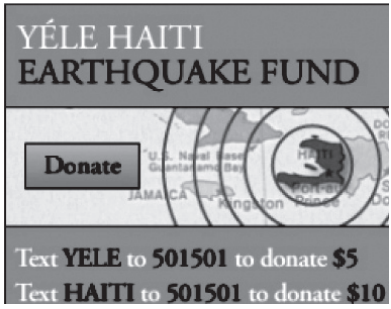

Figura 1: link para redes sociais

Fonte: yele.org

Encontrou-se outro perfil no Twitter que reforça a idéia de jornalismo participativo, o Haiti. org (haitibr), cujo propósito é informar seus seguidores dos últimos acontecimentos da região. $\mathrm{O}$ Twitter esta linkado com o web 
site (http://haiti.org.br_) diferenciando-se de outros do gênero pela sua criação e abastecimento de informações ser realizado por jornalistas, sendo responsáveis pelo perfil os profissionais Alo- ísio Milani, Rodrigo Savozoni e André Deak. Assim como o usuário projeta-se no lugar dos jornalistas, os jornalistas apropriam-se das redes sociais para divulgarem seus conteúdos.

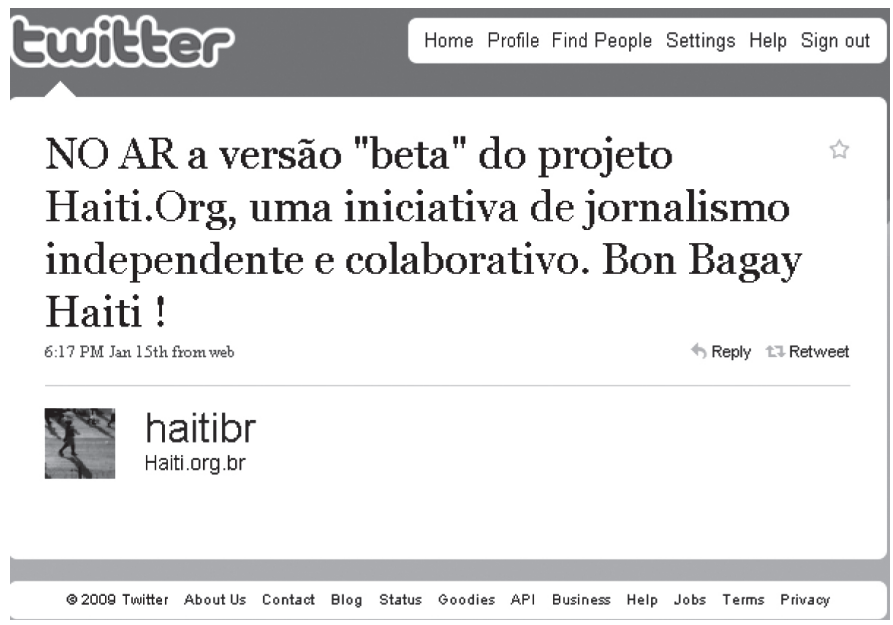

Figura 2: perfil de jornalismo independente

Fonte: twitter.com

O jornalismo participativo desperta preocupações com as formas tradicionais de se abordar a notícia. O site "observatório da imprensa" publicou que em meados de fevereiro deste ano, cinco jornalistas franceses ficarão confinados em uma fazenda, com o objetivo de testar a qualidade das notícias nas redes sociais da internet. A matéria comenta que a cada dia as redes sociais estão mais presentes nos fatos cotidianos e que "o Twitter mais uma vez desempenhou papel fundamental no Haiti, atingido por um terremoto, com usuários postando informações, fotos e pedidos de ajuda". $\mathrm{O}$ grande objetivo é verificar se as informações obtidas através das redes sociais são corretas e suficientes para a população ficar informada. Para isso, os jornalistas não terão acesso a nenhum outro meio de comunicação. "Esta iniciativa irá nos permitir analisar atentamente os mitos existentes sobre Facebook e Twitter. Nosso objetivo é mostrar que há diferentes fontes de informações e olhar para a legitimidade de cada uma destas fontes", comenta Helene Jouan, editora da France Inter, uma das emissoras participantes do projeto.

As opiniões jornalísticas sobre o uso da ferramenta são distintas, Tiago Dória, jornalista do "observatório da imprensa" coloca-se favorável a participação dos cidadãos publicando matéria com o intuito de divulgar sua opinião, cujo tema: "Haiti: postura da mídia mudou em relação à cobertura cidadã". Dória comenta que as primeiras informações sobre a catástrofe foram divulgadas por cidadãos comuns, e não pela imprensa e que isso representa mudanças na postura dos cidadãos. A mobilidade e os aparatos tecnológicos propicia- 
ram a rapidez na informação e nos processos comunicacionais. Comenta ainda, que na catástrofe do Tsumami, em 2004, as ferramentas embora existentes, não tinham credibilidade pela fonte da informação não ser primária, gerando dúvidas. Mas recebia inúmeros posts em seu site de pessoas querendo ajudar, o que considerou como um marco profissional. "Aliás, está virando praxe quando acontece uma tragédia, a imprensa correr para Orkut, Facebook, Flickr, Twitter e YouTube para colher os primeiros relatos, fotos e vídeos". (Tiago Dória)

\section{Considerações Finais}

O processo comunicacional passa por mutações, onde o cidadão comum participa ativamente contribuindo com informações e o profissional de jornalismo descobre novas formas de interagir com este usuário. As plataformas on-line e a mobilidade propiciada pela tecnologia são os principais atrativos impulsionadores de mudanças nos hábitos comportamentais. Anteriormente a informação era transmitida, quase que em sua totalidade, pelos meios de comunicação tradicionais; esperava-se o jornal da noite para nos informarmos dos fatos ocorridos durante o dia. Levavam-se horas para ter acesso a informações nacionais e internacionais.

$\mathrm{O}$ advento da internet mudou a cultura dos indivíduos, que participam dos produtos midiáticos sem ganharem por isso. Contribuem pelo fato de estarem inclusos no meio, de poderem pertencer ao grupo, de exercerem o papel de cidadãos. O grande desafio é a população saber o real poder que a informação tem, o que as mensagens levam consigo e quais os reflexos de um possível engano neste processo.

O profissional de jornalismo é preparado para pesquisar assuntos de interesse geral e publicá-los, saber escrevê-lo da forma mais correta e utilizá-lo em benefício do bem comum. Será que todos os cidadãos estão preparados para manusear o poder da informação? Ainda não se encontrou resposta final para esta questão, mas o fato é que os usuários comuns representam um número grande indivíduos que somados, ultrapassam o número dos profissionais da informação.

Durante pesquisas sobre o "Haiti" e as "Redes Sociais", encontraram-se vários artigos e links cuja abordagem principal era a amplitude das novas tecnologias e culturas sociais no âmbito da informação. O que parecia anteriormente como um passa tempo ocupa um novo papel, o social. A migração entre emissor e receptor é visível, e os estudos da comunicação adotam novas nomenclaturas para definir estes papeis, a palavra "receptor"é substituída por "interagente", aquele que interage com a mensagem, recebe e remete. No caso específico para o artigo, a pesquisa foi realizada apenas no Twitter por recorte de análise. Faz-se importante lembrar que o leque de canais de informações é infinito possibilitando desdobramentos diferenciados dependendo do local pesquisado.

As teorias sociais mostram a diferença entre os indivíduos e as mutações ocorridas decor- 
rentes dos fenômenos ocasionados pelo meio em que vivem. Este é mais um exemplo da teoria weberiana apresentada nos temas cotidianos, cujos fatores culturais e familiares, transformaram o indivíduo em cidadão e este cidadão como ferramenta do jornalismo participativo. Embora a teoria sociológica indique a transformação deste individuo decorrente das diferentes situações, não podendo o generalizar, percebe-se que o ser humano tem a capacidade de mobilização em relação a outros indivíduos. Em casos extremos, como este do Haiti, pessoas diferentes e tão distantes sem laços afetivos mostram-se unidas em prol à causa com vontade de ajudar $\mathrm{e}$ informar.

\section{Referências}

BAURDIEU. Pierre. A Economia das Trocas Simbólicas. Editora Perspectiva. São Paulo, 1992.

DATAFOLHA. Instituto de Pesquisa. Pesquisa sobre a população jovem. Disponível em: <http://datafolha.folha.uol.com.br/po/ver po.php?session=700>. Acesso em: 05/12/2009.

DORIA, Tiago. Haiti: Postura da mídia mudou em relação à cobertura cidadã. Disponível em: http://www.observatoriodaimprensa.com. br/artigos. asp?cod=573ASP009. Acesso em 29/01/2010.

GLOBO.COM. Voluntários pedem ajuda e usuários do Twitter fazem campanhas por doações ao Haiti. Disponível em: <http://oglobo. globo.com/mundo/mat/2010/01/15/voluntarios-pedem-ajuda-usuarios-do-twitter-fazem-campanha-por-doacoes-para-haiti-915533386. asp >. Acesso em: 27/01/2010.

HAITI.ORG. Disponível em: <http://haiti.org.br/about/>. Acesso em 28/01/2010.

KUSCHI, Murilo. Weber e a sua relação com a Comunicação. Organização: Marocco, Beatriz; Berger, Christa. A Era Glacial do Jornalismo - teorias sociais da imprensa. Editora Sulina, 2006.

M\&M. Jornal Meio e Mensagem. Twitter é rede de informação e não mídia social. Disponível em: $<$ http://www.mmonline.com.br/noticias. mm? url=Twitter_e_rede_de_informacao $>$. Acesso em: 20/01/2010.

M\&M. Jornal Meio e Mensagem. Em um ano acesso da web cresce 10\%. Disponível em: <http://www.mmonline.com.br/noticias. mm?url=Em_um_ano,_acesso_a_web_cresceu_10_porc_\&origem $=$ mmbymail\&token $=482441285171185-115351613>$. Acesso em: 20/01/2010. 
M\&M. Jornal Meio e Mensagem: Twitter, canal de solidariedade para as vítimas do Haiti. Disponível em: <http://www.mmonline.com.br/ noticias.mm?url=Os_detalhes_da_Geracao_Y\&origem $=$ mmbymail $\&$ token $=482441285171185-11 \overline{5} 351613>$. Acesso em: 20/01/2010.

PINHO, J. B. Jornalismo na Internet. Planejamento e Produção de informação on-line. Summus Editorial. São Paulo, 2003.

R7. Haiti inunda o Twitter. Disponível em: < http://noticias.r7.com/ tecnologia-e-ciencia/noticias/depoimentos-e-imagens-do-haiti-inundam-o-twitter-20100113.html>. Acesso em 25/01/2010.

TWITTER. Jornalistas se isolam para testar twiter e facebook. Disponível em: http://www.observatoriodaimprensa.com.br/artigos. asp?cod=574MON006. Acesso em 29/01/2010.

WEBER, Weber. Sociologia da Imprensa: um programa de pesquisa. Organização: Marocco, Beatriz; Berger, Christa. A Era Glacial do Jornalismo - teorias sociais da imprensa. Editora Sulina, 2006.

WEBER. Max. Disponível em: <http://www.pensador.info/autor/ Max_Weber/biografia/>. Acesso em: 20/11/2009.

WEBER. Max. Economia e Sociedade. Volume I. Editora UNB. Brasília, 1972. 